\title{
BILATERAL WILMS' NEPHROBLASTOMA
}

\author{
BY \\ GERALD B. DOYLE \\ From the Department of Pathology, Coventry and Warwickshire Hospital, Coventry
}

(RECEIVED FOR PUBLICATION OCTOBER 17, 1955)

Comparatively few cases of bilateral Wilms' tumour have been described in the past 55 years. In 1897, Walker reviewed the literature over the previous 100 years and found 141 cases of Wilms' tumour of which 10 were said to be bilateral, but he gave no details of these. Hedrén (1907) described a remarkable case with apparent multicentric origin in both kidneys. In 1931, Kretschmer and Hibbs found two cases in a review of 17. Other isolated reports followed. Ueda (1935) recorded a single case; Ladd (1938) found one case in 45 reviewed; Herzog (1939) quoted some reports from the European literature of which two occurred in this century (Jemma, 1922; Nevinny, 1926). Campbell (1948) reported two cases diagnosed at necropsy; Barr and Schulte (1950) and Rusche (1951) recorded one case each. In a review of 74 cases diagnosed at The Hospital for Sick Children, Great Ormond Street, London, from 1925 to 1951, only one bilateral case occurred (British Empire Cancer Campaign Report, 1951), while a survey of the material in the Boston Children's Hospital, 1914-47, disclosed four cases in a total of 96 (Gross, 1953). Sheach (1953) added another report. The following description concerns a further case in a girl.

\section{Case History}

The patient was a girl of 3 years who had a fall while playing in the road. Radiographs at the time of this mishap showed no fracture of the dorsal or lumbar spines and no abnormality of the chest. In the following two months she had occasional bouts of vomiting and her mother noticed a gradual enlargement of the abdomen. Eventually the child was brought to her doctor who arranged admission to the City Hospital, Nottingham.

Examination revealed a pale, irritable child with a distended abdomen. There were some prominent veins on the abdominal wall, and a soft, painless mass could be palpated on the right side. There was no visible peristalsis. The child was apyrexial, and there were no enlarged tonsils or palpable lymph nodes, nor was there any evidence of cardiac or respiratory abnormality. Urinary examination showed a few red blood cells in the uncentrifuged specimen, but nothing else of note. A blood count gave haemoglobin $8 \cdot 4$ g., R.B.C. $4,050,000$ per c.mm., W.B.C. 8,500 per c.mm. (polymorphs $52 \%$, lymphocytes $45 \%$, monocytes $3 \%$ ).

A straight radiograph of the abdomen showed a large opacity due to a mass of soft tissue. Further investigations were precluded by the general poor condition of the child. Shortly afterwards she became extremely shocked and collapsed. A paracentesis abdominis was performed and about half a pint of straw-coloured fluid was aspirated. The patient's condition slowly deteriorated and she died the same day.

Necropsy. The body was that of a well developed but rather emaciated female child. There was some mucopus in the bronchioles. The heart was of normal pattern. The abdomen contained a large tumour mass in the region of each kidney (Fig. 1). The mass on the right side was the larger and on section appeared cystic; the cystic spaces, containing gelatinous material, were separated by wide bands of tumour tissue. The kidney was recognizable in the tumour mass. On the left side, beneath the capsule of the growth, there was recent haemorrhage which appeared to have originated within the tumour. The left kidney was also involved in the growth. There were a few enlarged lymph nodes near the mid-line but these showed no malignancy. The liver and spleen showed marked toxic changes. The other abdominal organs showed nothing of note.

Sections of both tumours showed the typical pattern of Wilms' nephroblastoma (Fig. 2). Sheets of undifferentiated tissue of embryonic type surrounded clumps of epithelial cells in which there were tubules of varying development.

\section{Discussion}

The rarity of bilateral Wilms' tumour suggests that such cases as do occur are usually multifocal in origin, and that direct extension from one kidney to another is unusual. Direct spread has occurred on occasion as in Kretschmer and Hibbs's second case (1931), but in most of the reported cases, including the present one, separate tumours appear to have originated in both kidneys.

The majority of cases terminate fatally, and death in this instance was almost certainly due to the severe haemorrhage occasioned by the rapidly growing tumour on the left side. 


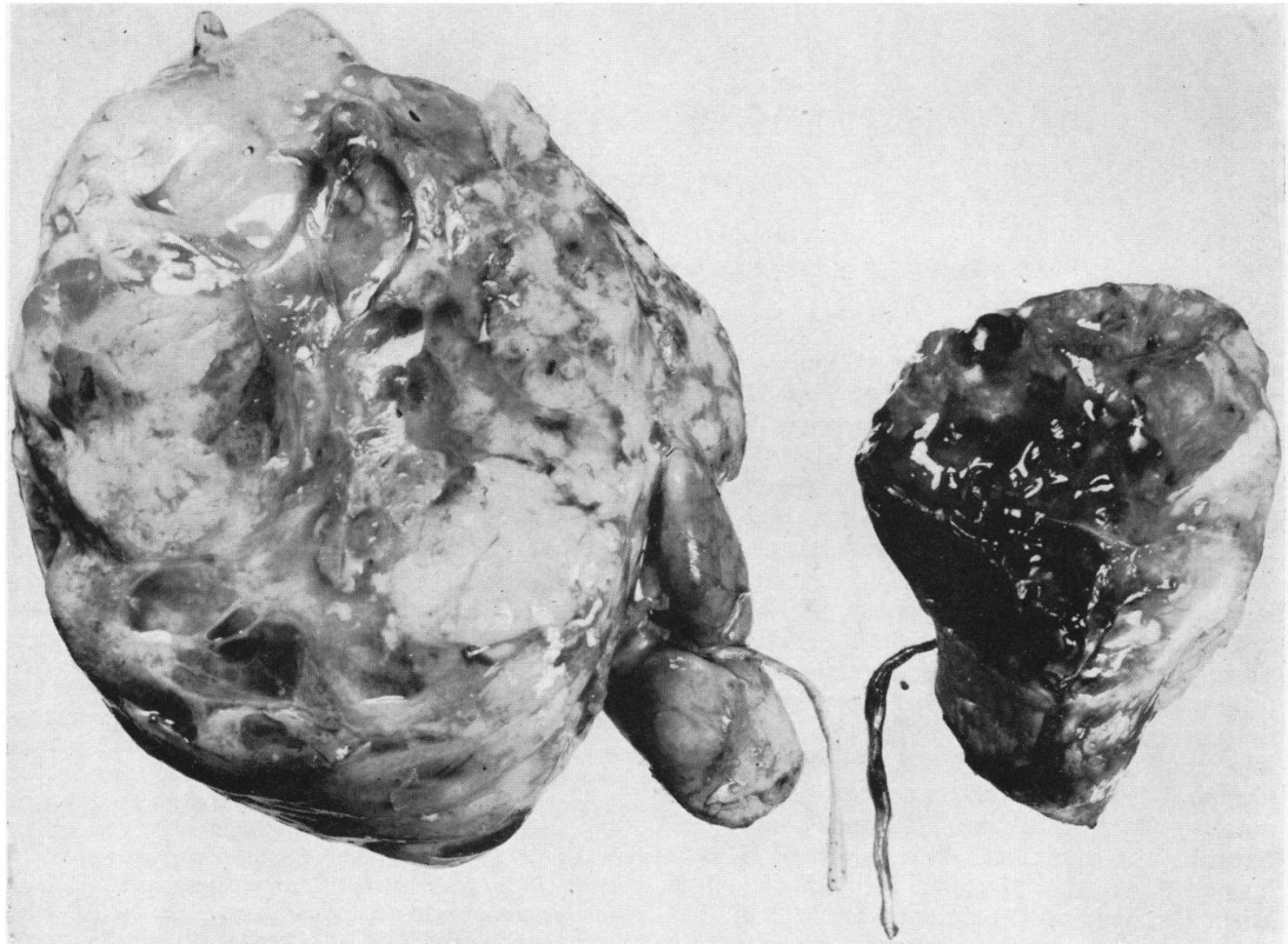

FIG. 1.-Cut section of tumours showing the right kidney and the haemorrhage on the left side.

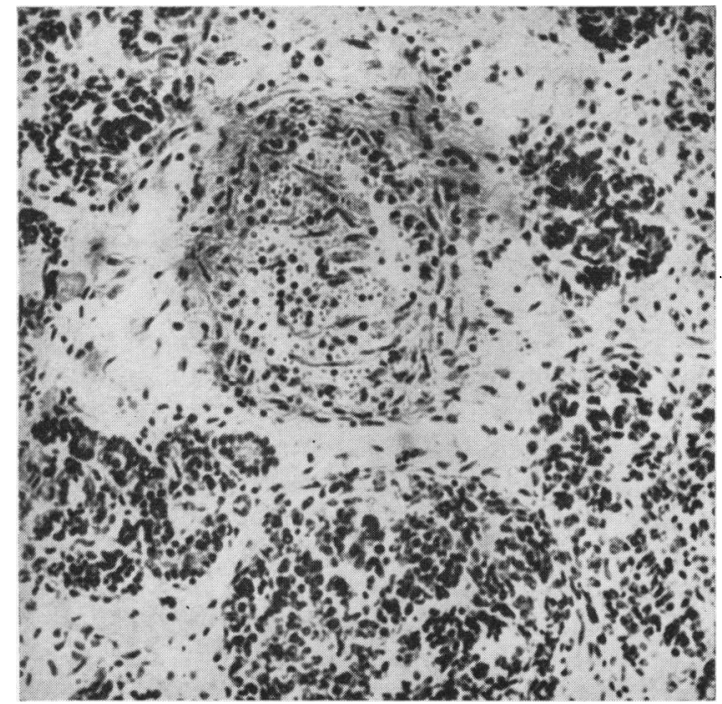

FIG. 2.-Typical Wilms' nephroblastoma with many small tubular structures. Haematoxylin and eosin $\times 100$.

\section{Summary}

A case of bilateral Wilms' nephroblastoma is recorded with a brief enumeration of the other cases in the literature of this century.

I am indebted to Dr. A. P. M. Page under whose care the patient was admitted to hospital.

\section{REFERENCES}

Barr, J. R. and Schulte, J. W. (1950). West J. Surg., 58, 567. British Empire Cancer Campaign 29th Annual Report (1951) pp. 133-42. London.

Campbell, M. F. (1948). J. Urol., 59, 567.

Gross, R. E. (1953). The Surgery of Infancy and Childhood, p. 602 Philadelphia.

Hedrén, G. (1907). Beitr. path. Anat., 40, 1.

Herzog, H. (1939). Z. Krebsforsch., 48, 424. Jemma, G. (1922). Pediatria (Napoli), 30, 314. Quoted by Herzog

Kretschmer, H. L. and Hibbs, W. G. (1931). Surg. Gynec. Obstet.

Ladd, W. E. (1938). Ann. Surg., 108, 885.

Nevinny, H. (1926). Z. urol. Chir. (Orig.), 20, 295. Quoted by Herzog (1939).

Rusche, C. (1951). J. Urol., 65, 950.

Sheach, J. M. (1953). Brit. J. Urol., 25, 109.

Ueda, T. (1935). Jap. J. Derm. Urol. (German abst.), 37, 75.

Walker, G. (1897). Ann. Surg. 26, 529. 